\title{
Patterns of hedgehog inhibitor (HHI) treatment interruptions and reinitiations among patients with basal cell carcinoma (BCG) in real-world clinical practice
}

Jessica J Jalbert, ${ }^{1}$ Chieh-I Chen, ${ }^{1}$ Ning Wu, ${ }^{1}$ Matthew G Fury, ${ }^{1}$ Emily Ruiz, ${ }^{2}$ Wenzhen Ge 'Regeneron Pharmaceuticals, Inc., Tarrytown, NY, USA; 'Brigham and Women's Hospital, Boston, MA, USA
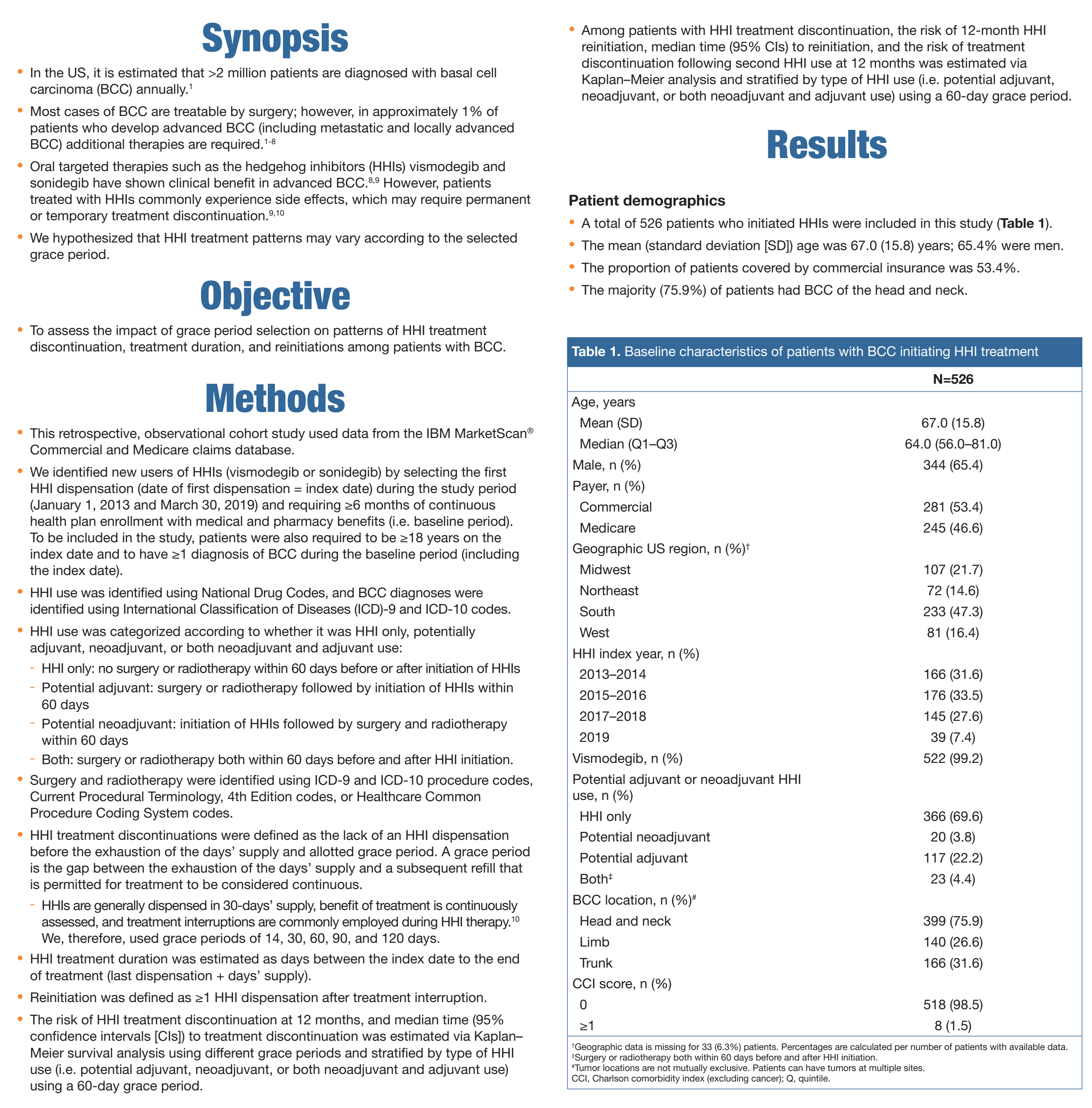

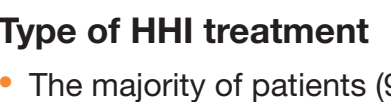

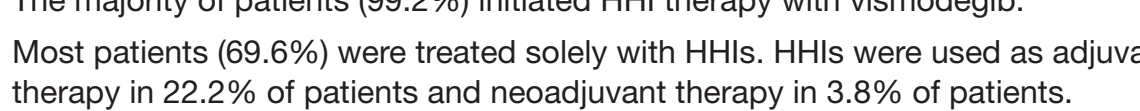
atterns of HHI discontinuations using different grace periods Risk of treatment discontinuation at 6 monthrs ranged from $78.8 \%$ when requiring
a 14-day grace period to $5.5 \%$ when requiring a 120 -day grace period (Figure 1)

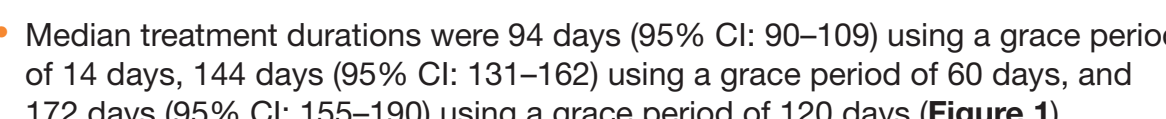
Patterns of $\mathrm{HHI}$ reinititition using different grace periods $\begin{array}{ll} & \\ & \end{array}$

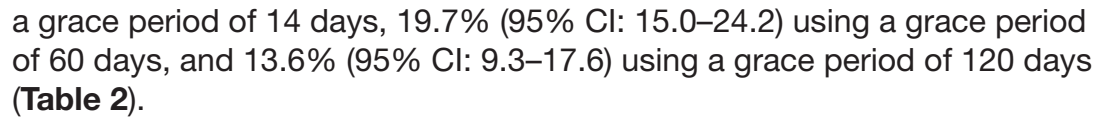

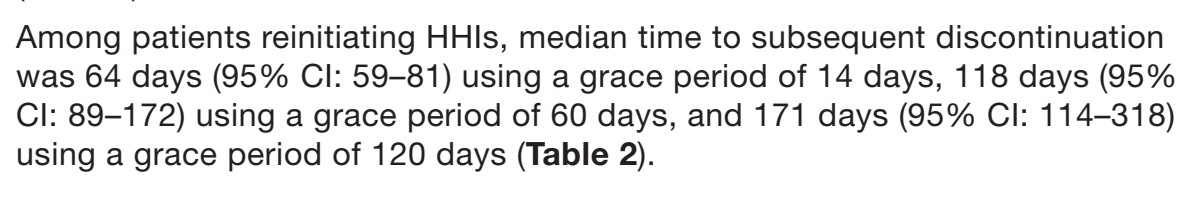

Patterns of $\mathrm{HHI}$ disco
by type of HHI use

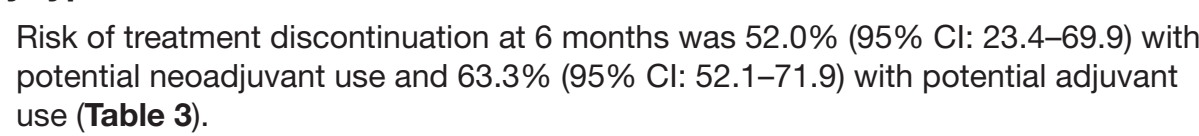

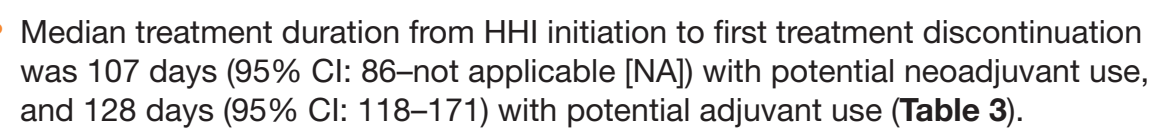
Patterns of HHI reinititition using a 60-day grace period, stratified by

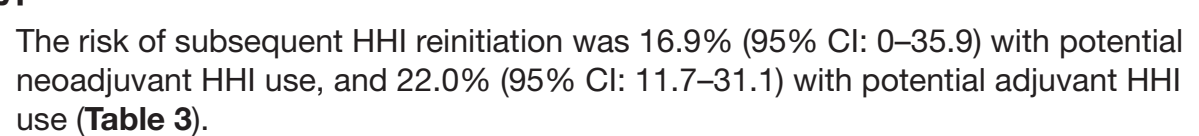

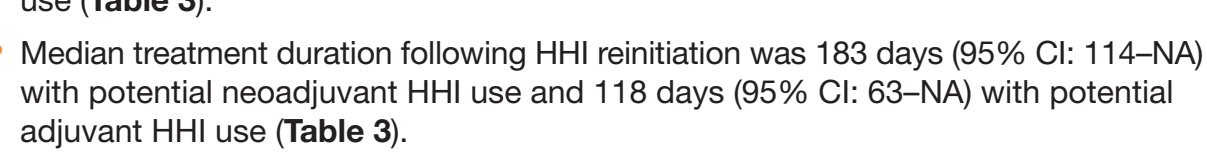
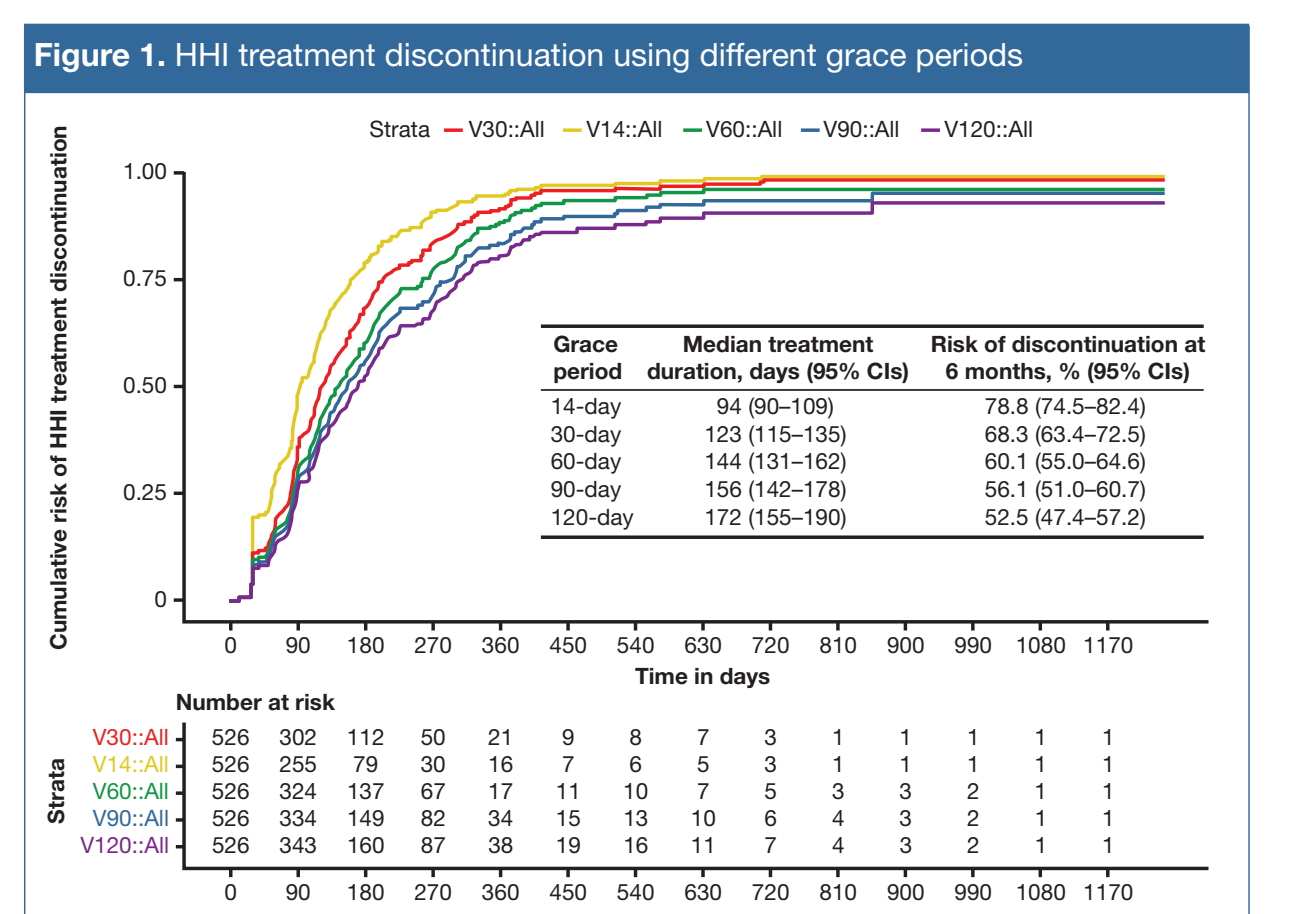

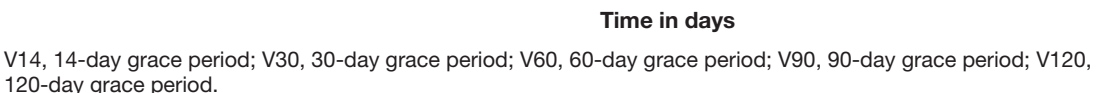
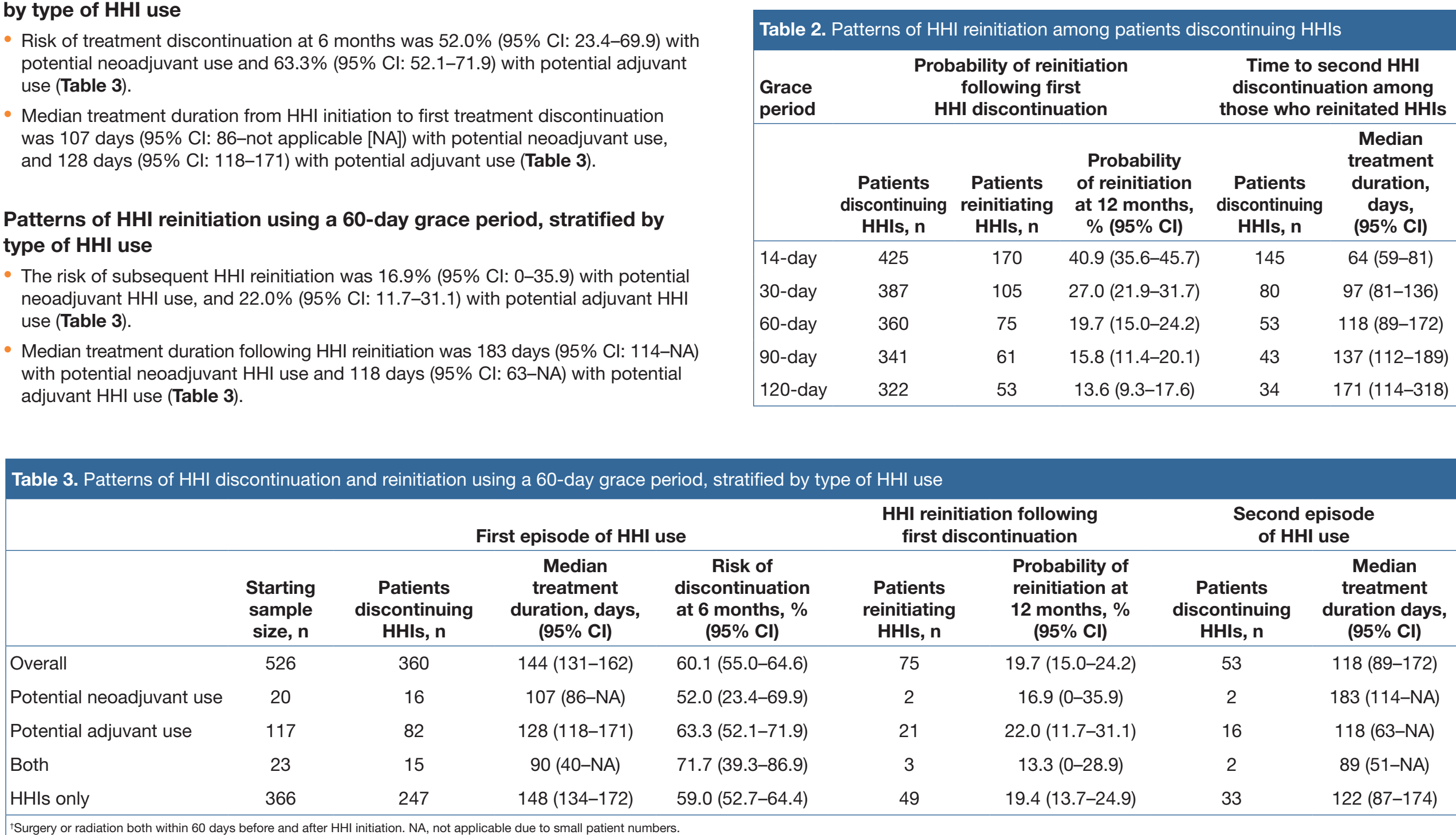

Limitations

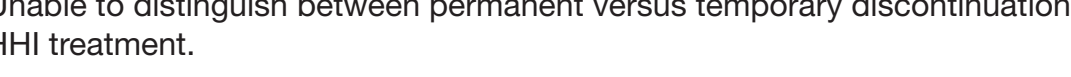

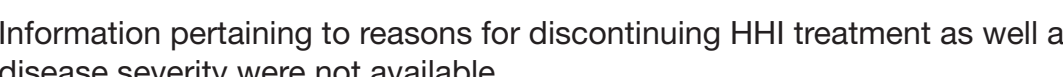

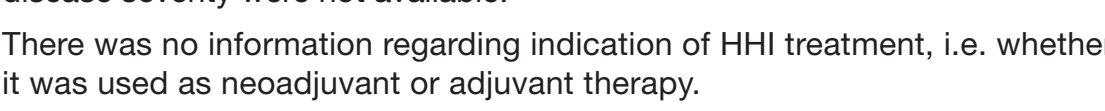

Summary and Conclusion The majority $(-999 \%)$ of patients inititated vismodegib.
Most patients $(-70 \%$ ) used HHIs alone versus using HHIs as potent neoadijuvant or adjuvant treatment.
- Athougn varability was observed based on the selecteded grace period, median
treatment duration was $<180$ days even when using a 120 -day yrace period. Median duration of $\mathrm{HH}$ HItreatment was considerably shorter than the median
treatment turation $(8.6-13.3$ months $)$ reported in the pivotal clinical trials

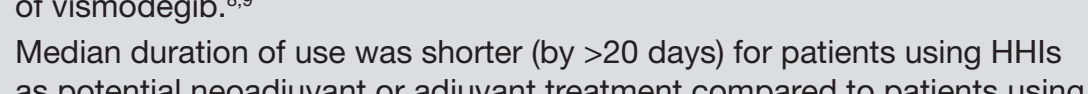
as potential nea
HHIl monotheraty

The probability of $H$ HI r renintiation within 12

vithin 12 months of discontinuation was

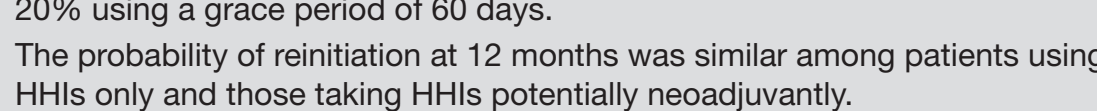

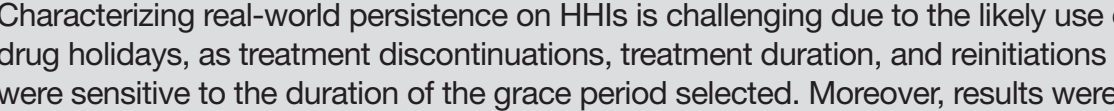

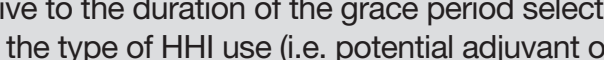

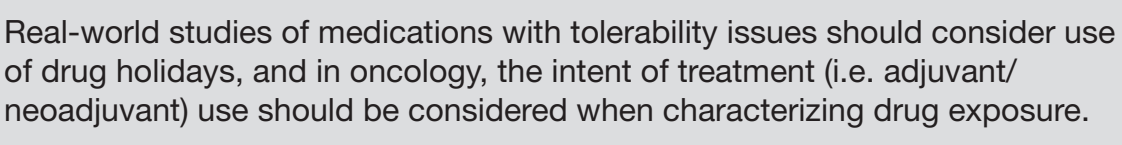

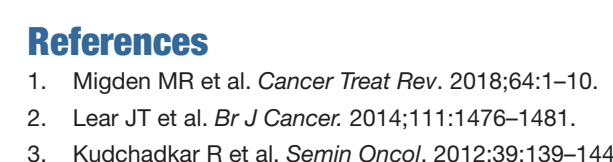

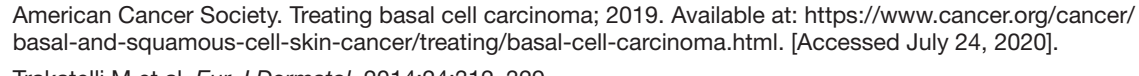

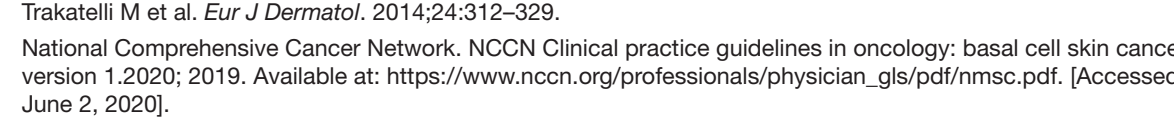

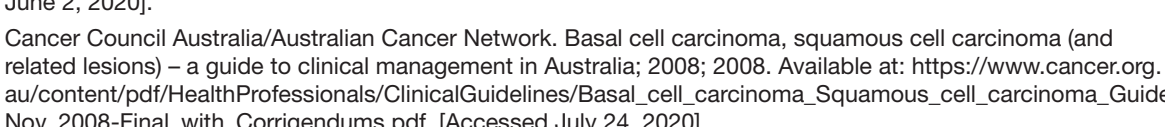

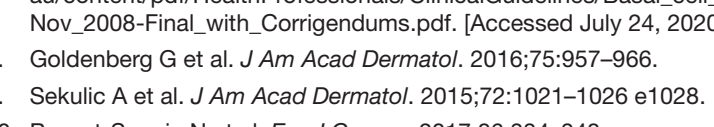

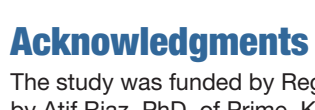

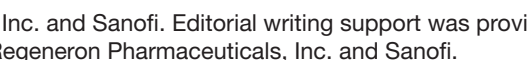

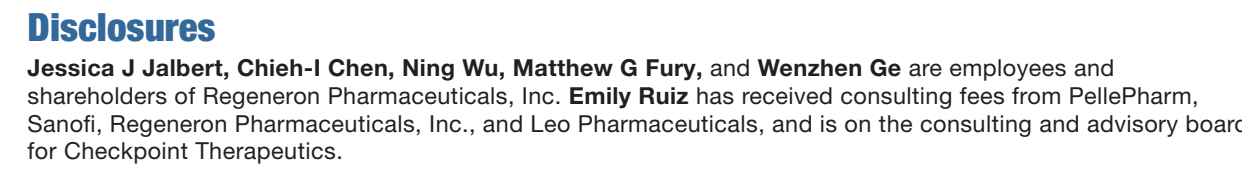

